\title{
Spain's ill-conceived project leaves its scientists in the lurch
}

Come 15 November, Xavier Fernàndez-Busquets will be out of a job.

A researcher at the prestigious Barcelona Science Park, Fernàndez-Busquets was full of optimism in 2001, when the Spanish government with much fanfare launched the Ramón y Cajal program. The scheme was intended to lure back young scientists working abroad and boost Spain's ailing research system.

Since then, enticed by the chance to be back in their home country, thousands of researchers have left permanent or tenure-track positions in other countries to return to Spain.

Two months before the end of the first set of contracts, however, many RyCs, as the fellows call themselves, find themselves without any long-term possibilities. Of 619 RyCs surveyed in February by the National Association of Ramón y Cajal researchers, a third said they had no clear prospects of a job when their contract ended.

Left in limbo, Fernàndez-Busquets is closing down his research projects and helping his two graduate students finish their PhDs. "Most likely by November 15 nothing will be solved," he says. "I'm disappointed at the lack of planning."

Despite repeated attempts, none of various members of Spain's Ministry of Education and Science contacted by Nature Medicine responded to queries.

Spain's spending on science is among the lowest in Europe and its institutes are plagued by brain drain, cronyism and a shortage of funds. The RyC program was a welcome change and aimed to build a critical mass of scientists.

Between 2001 and 2003, the government gave out 800 contracts each year, and in each of the years since, it gave out 250-although some recipients have left either the country or even science. Initially, the contracts were positioned as 'tenure-track' positions and offered the researchers about $€ 30,000$ for five years, a

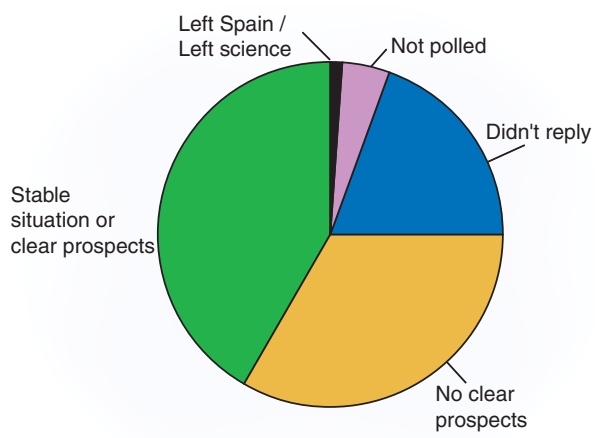

National Association of Ramón y Cajal fellows poll February 2006

Poor planning: About a third of Ramón y Cajal fellows are looking for last-minute solutions. startup fund of $€ 6,000$ per year and a light teaching load.

In many ways, the RyCs are like professors: they have their own students, set their own research direction and apply for their own grants. But the fellows soon discovered that the contracts are in reality more like postdoctoral fellowships. Neither the government nor the universities had planned beyond the five-year period. "It was tenure track without tenure. It was just a track," says Jordi Villà i Freixa, an RyC fellow at the Parc de Recerca Biomèdica de Barcelona.

"2006 marks the 100th anniversary of the first Nobel Prize in Physiology or Medicine to a Spaniard, Santiago Ramón y Cajal, who gives the name to the program," Villà i Freixa says. "It is a pity that such a wonderful event will be associated with the sweet/sour taste the RyC program has left."

The RyCs have had to constantly jump through hoops. Although they have already had years of postdoctoral experience, they are evaluated every two years, and only those who pass continue in the program. Many have won lucrative grants from the government and published papers in prestigious journals. Despite all this, "my professional and economical futures are right now unpredictable," says Ana Guadaño Ferraz, a fellow at the national research council Consejo Superior de Investigaciones Científicas.

Part of the problem, the fellows say, is that the government launched an ambitious scheme without consulting with the universities. Universities receive money from the government based on the number of undergraduate students enrolled. Their focus naturally is more on teaching rather than on research, and most of them cannot afford to absorb professors who would only do research. "Eventually, it's all a matter of funding," says Enric Claverol-Tinturé, a 2003 RyC fellow who left a tenure-track position at Los Alamos National Laboratory to return to Spain.

At times, the RyCs have also had to fight for recognition.

In April 2003, after an article in Science referred to them as "new postdocs," 117 RyCs wrote to the magazine, detailing their complaints. In June 2006, M.A. Quintanilla, the newly nominated Secretary of State for Universities and Research, set off a furor when he called the positions "temporary postdoctoral contracts." Furious fellows bombarded the RyC email list with messages and demanded his resignation. "After five years, the situation is very dark for most of us," said one email circulated to members of the press. "We feel deeply disappointed by the lack of respect."

Most RyCs only came back to Spain because they were led to believe that the positions were tenure track, adds Villà i Freixa. "When you have 800 labs, a lot of people are depending on them, a lot of projects. It's a mess," he says. "The RyC program seems to be just the tip of the iceberg of the lack of long-term science policy in the country."

Villà i Freixa is safe for the moment. He was among 300 scientists-including non-RyCswho qualified for the government's I3 program, launched in 2005. Under this scheme, the government pays for researchers at a university for three years, buying them more time to find a permanent position.

In the absence of a long-term national plan, many of the regional governments have come up with their own solutions. All regions except the Basque country, for instance, have adopted the I3 program. Some regions such as Cantabria that have few RyCs are giving out permanent contracts to the fellows. Valencia created a foundation that can hire RyCs without the open competition normally required for new positions. "Everyone is coming up with different ideas of how to do it. It's crazy," says Claverol-Tinturé.

Claverol-Tinturé is a member of the RyC team that is negotiating with the Catalan government to find jobs for RyCs.

In 2001, the Catalan government launched the ICREA tenure track program for senior scientists, but the highly competitive program can help only a few researchers. In talks in mid-September, the Catalan government seemed ready to reach an agreement with universities to help those who haven't been picked up by ICREA or I3.

With upcoming elections scheduled for 1 November, "whatever has to be done, it has to be decided quickly in the next five weeks," says Fernàndez-Busquets. "But it has to happen because otherwise it'll be a catastrophe. It cannot be that they leave us stranded."

Apoorva Mandavilli, Barcelona 